\title{
A comparative Analysis of Antioxidant capacity of aqueous and methanolic leaf extracts of Scoparia dulcis and Schleichera oleosa
}

\author{
Sophy Jose*, M. P. Sinha
}

* Corresponding author: Sophy Jose, E-mail: josesophy35@gmail.com

\section{*Department of Zoology, Ranchi University, Ranchi-834008, Jharkhand, India.}

\begin{abstract}
In this study a comparative analysis of total anti-oxidant capacity of aqueous and methanolic leaf extracts of Scoparia dulcis and Schleichera oleosa was done by estimation of DPPH radical, hydroxyl radical, superoxide anion radical and nitric oxide radical scavenging activity. The methanolic extract (M.E) of S.oleosa showed a maximum concentration of total phenolics and flavanoids up to $20 \%$ and $168.89 \%$ and aqueous extract (A.E) showed a maximum concentration of total phenolics and flavanoids up to $4.90 \%$ and 9.33\% respectively. The M.E of S.dulcis showed a maximum concentration of total phenolics and flavanoids up to $6.21 \%$ and $9.24 \%$ and A.E $46.22 \%$ and $14.67 \%$ respectively. Free radical scavenging activity was observed in both the M.E and A.E. For S.dulcis the \% of free radical activity in M.E and A.E in $100 \mu \mathrm{g}$ concentration was $2.98 \%$ and $15.53 \%$ respectively. M.E and A.E of S.oleosa showed $54.94 \%$ and $5.93 \%$ free radical scavenging activity correspondingly. Hydroxyl scavenging activity for $100 \mu$ g of S.dulcis extracts were $17.92 \%$ in M.E and $11.39 \%$ in A.E where as for S.oleosa extracts it was 35.83\% and 8.19\% in M.E and A.E respectively. S.dulcis showed only $4.03 \%$ and $3.23 \%$ scavenging of superoxide anion radical and S.oleosa showed superoxide anion scavenging up to $22.58 \%$ in M.E and 3.23\% in A.E. Nitric oxide scavenging activity was 5.71\% in M.E of S.dulcis and 5.24\% for A.E where as S. oleosa showed 33.81\% nitric oxide scavenging activity in M.E and $31.43 \%$ in A.E. The presence of phenol, flavonoid and total antioxidant in both the extract justifies the antioxidant potential of the plants which brings about their free radicals scavenging potential. Thus we conclude that the antioxidant activities may be due to the cumulative effect of the phytochemicals present in the plant which genuinely designate them as free radical scavengers.
\end{abstract}

Key words: Extracts, Total phenolic compounds, Total flavonoids, NO radical, DPPH radical, hydroxyl radical, superoxide anion radical

Introduction. Energy to fuel biological processes is produced by oxidation in many living organisms. However, there are many reactive oxygen species and free radicals that are associated or formed as a result of the oxidation process. These reactive species often cause cell death and are involved in other degenerative processes associated with ageing (Halliwell and Gutteridge 2003). Reactive oxygen species (ROS) along with free radicals are also found to play a role in functional changes associated with diseases like cancer, rheumatoid arthritis, cirrhosis etc. Exogenous chemical and endogenous metabolic processes in the human body or in the digestive system might produce highly reactive free radicals, especially oxygen derived radicals, which are capable of oxidizing biomolecules, resulting in cell death and tissue damage. (Mau et al., 2001) Cells are equipped with enzymes like superoxide dismutase, catalase and also chemicals like vitamin $\mathrm{E}$, vitamin $\mathrm{C}$, polyphenols, carotinoids and glutathione (Niki et al., 1994) to neutralize the damage caused by the radicals. These are endogenous antioxidants produced within the body to scavenge free radicals are not adequate to remove them fully and to maintain a balance (Jose, et al., 2016). The use of synthetic antioxidants such as butylated hydroxyanisole (BHA), butylated hydroxytoluene (BHT), Propylgallate (PG) and butylated hydroquinone have often been implicated to achieve immediate result, recent data indicates that these synthetic antioxidants could have carcinogenic effects thus fuelling an intense search for newer and efficient antioxidants (Yevgenia et al., 2013). Antioxidant containing natural foods can however be used to reduce the oxidative damage (Mau et al. 2001; Gülçin et al., 2002).

Scoparia dulcis commonly called as sweet broom weed is a perennial herb, widely distributed in tropical and subtropical regions. Traditionally it has been used as remedies for varieties of ailments like stomach troubles, hypertension, diabetes, inflammation, bronchitis, hemorrhoids, hepatosis, analgesic, diuretic, antipyretic and cytotoxicity (Freire et al., 1993; Hayashi et al., 1993; Ahsan et al., 2003).

Schleichera is a genus of plants in the soapberry family, Sapindaceae and is generally found in Indian subcontinent in mixed deciduous forests and in Southeast Asia. It is used in traditional medicine systems and its leaf, seed, oil and bark are used for curing itch, burns, acne pain in the back and 
loins etc. and it promotes hair growth, treats rheumatism, head ached, skin diseases, malarial fever and is prophylactic against cholera [Palanuvej et al., 2008].

Scoparia dulcis and Schleichera oleosa have high medicinal value and are easily available common plants which can be used in anti-oxidant therapy as well as other curative practice (Jose and Sinha. 2017). Thus, showing the potential medicinal efficacy of each extracted compounds present in the plant, permits not only the demonstration of their physiological activity but also facilitates pharmacological studies leading to synthesis of more potent drugs with reduced toxicity (Manna and Abalaka, 2000). Hence, it is important to compare the antioxidant efficacy of $S$. dulcis and $S$. oleosa.. Therefore present study was undertaken to compare the antioxidant capacity of aqueous and methanolic leaf extracts of Scoparia dulcis and Schleichera oleosa.

\section{MATERIALS AND METHODS}

\section{Collection of plant materials}

The fresh mature leaves were collected, dried in shade under room temperature for six to seven days and then crushed into coarse powder using electric grinder. The powder was sieved to get fine powder using fine plastic sieve which was stored in air tight bottle in the laboratory until required.

\section{Extract preparation}

$50 \mathrm{~g}$ of the powder was subjected to extraction by soxhlet using methanol and distilled water separately. The extracts obtained were filtered, concentrated after dryness in rotary flash evaporator maintained at $45^{\circ} \mathrm{C}$., percentage yield of each extract was calculated and the dried extracts were stored in air tight containers at room temperature for further studies.

\section{Phytochemical analyses}

Freshly prepared extracts of the powdered leaves were subjected to phytochemical analyses to find the presence of the following phyto constituents such as flavanoids, alkaloids, carbohydrates, glycosides, polysaccharides, tannins, saponins, steroids, proteins, lipids, oils by standard methods.[ Trease and Evans, 2002; Sofowara, 2008].

\section{Estimation of total phenolics}

Known amount of sample were pipetted out in series of test tubes and volume was made up to $3 \mathrm{ml}$ with distilled water. Folin-Ciocalteau reagent $(0.5 \mathrm{ml})$ was added to each tube and incubated for $3 \mathrm{~min}$. at room temperature Sodium carbonate $(20 \% ; 2 \mathrm{ml})$ solution was added, mixed thoroughly and the tubes were incubated for $1 \mathrm{~min}$. in boiling water bath. Absorbance was measured at 650nm against a reagent blank. Standard curve using different concentrations of standard phenolic -catechol was prepared. From the standard curve, concentration of phenols in the test samples was determined and expressed as mg of catechol equivalent. (Malick, et al., 1980) The values are furnished in Fig.1.

\section{Estimation of flavonoids}

Known volume of samples was pipetted out in series of test tubes and volume was made up to $0.5 \mathrm{ml}$ with distilled water. Sodium nitrite $(5 \% ; 0.03 \mathrm{ml})$ was added to each tube and incubated for $5 \mathrm{~min}$. at room temperature. Aluminium chloride solution (10\%; $0.06 \mathrm{ml}$ ) solution was added and incubated for $5 \mathrm{~min}$. at room temperature. Sodium Hydroxide solution (1 $\mathrm{M} ; 0.2 \mathrm{ml}$ ) was added and total volume was made up to $1 \mathrm{ml}$ with distilled water. Absorbance was measured at $510 \mathrm{~nm}$ against a reagent blank. Standard curve using different concentrations of rutin was prepared. From the standard curve, concentration of flavonoids in the test samples was determined and expressed as mg of rutin equivalent. [Helmja, et al., 2007).The values are given in Fig.2.

\section{Estimation of total antioxidant activity}

The antioxidant properties of plant samples were determined by Spectrophotometric quantitation method (Prieto et al.,1999).Various concentrations of samples $(5 \mu \mathrm{g}, 50 \mu \mathrm{g}, 100 \mu \mathrm{g})$ were taken in a series of test tubes. The $1.9 \mathrm{~mL}$ of reagent solution $(0.6 \mathrm{~m}$ Sulphuric acid, $28 \mathrm{~mm}$ Sodium phosphate and $4 \mathrm{~mm}$ Ammonium molybdate) was added to the test tubes. The tubes were incubated at $95^{\circ} \mathrm{C}$ for $90 \mathrm{~min}$ and allowed to cool down. The absorbance of aqueous solution of each was measured at $695 \mathrm{~nm}$ against blank. Antioxidant capacities were expressed as equivalents of ascorbic acid. Butylated hydroxylanisole (BHA) was used as reference standard. 


\section{Estimation of free radical scavenging activity}

Different concentrations $(10 \mu \mathrm{g}, 50 \mu \mathrm{g}$ and $100 \mu \mathrm{g})$ of samples in Dimethyl sulfoxide (DMSO), were taken in a series of test tubes. The volume was adjusted to $500 \mu 1$ by adding Methanol. Five millilitres of a 0.1 mm methanolic solution of 1,1-diphenyl-2-picryl hydrazyl (DPPH; from Sigma -Aldrich, Bangalore) was added to these tubes and shaken vigorously. A control without the test compound, but with an equivalent amount of methanol was maintained. The tubes were allowed to stand at RT for $20 \mathrm{~min}$. The absorbance of the samples was measured at $517 \mathrm{~nm}$. Butylated Hydroxy Anisole (BHA) was used as reference standard. [ Kumar. et al, 2008)]: Free Radical scavenging activity was calculated using the following formula:

$\%$ radical scavenging activity $=(\underline{\text { control OD }- \text { sample OD }}) \times 100$.

Control OD

\section{Estimation of hydroxyl Radical Scavenging Activity}

Various concentrations $(10 \mu \mathrm{g}, 50 \mu \mathrm{g}$, and $100 \mu \mathrm{g})$ of samples in DMSO were taken in different test tubes and made up to $250 \mu \mathrm{l}$ with $0.1 \mathrm{M}$ phosphate buffer. One milliliter of iron-EDTA solution $(0.13 \%$ ferrous ammonium sulfate and $0.26 \%$ EDTA), $0.5 \mathrm{ml}$ of EDTA (0.018\%), and $1 \mathrm{ml}$ of Dimethyl sulphoxide $(0.85 \% \mathrm{v} / \mathrm{v}$ in $0.1 \mathrm{M}$ phosphate buffer, $\mathrm{pH}$ 7.4) were added to these tubes, and the reaction was initiated by adding $0.5 \mathrm{ml}$ of $0.22 \%$ ascorbic acid. These reaction mixtures were incubated at room temperature for 15 $\min$. The reaction was terminated by the addition of 1 $\mathrm{ml}$ of ice-cold TCA $(17.5 \% \mathrm{w} / \mathrm{v})$. Three milliliters of Nash reagent (150 g of ammonium acetate, $3 \mathrm{ml}$ of glacial acetic acid, and $2 \mathrm{ml}$ of acetyl acetone were mixed and raised to $1 \mathrm{~L}$ with distilled water) was added to all of the tubes and left at room temperature for 15 min for color development The intensity of the yellow color formed was measured spectrophotometrically at $412 \mathrm{~nm}$ against reagent blank. Ascorbic acid (AA) was used as reference standard. (Klein, et al., 1991).

The percentage hydroxyl radical scavenging activity was calculated by the following formula:

\% hydroxyl radical scavenging activity

$$
=1-\left(\frac{\text { difference in absorbance of sample }}{\text { difference in absorbance of blank }} \times 100\right)
$$

\section{Estimation of super oxide anion Radical}

\section{Scavenging Activity}

Nitroblue tetrazolium (NBT;150 $\mu \mathrm{M}$ in Tris-HCl buffer $16 \mathrm{mM} \mathrm{pH} 8.0 ; 1 \mathrm{ml}$ ) and Nicotinamide adenine dinucleotide (NADH; $234 \mu \mathrm{M}$ in Tris-HCl buffer $16 \mathrm{mM} \mathrm{pH} 8.0 ; 1 \mathrm{ml}$ ) were mixed in a series of test tube. Various concentrations $(10 \mu \mathrm{g}, 50 \mu \mathrm{g}$ and $1000 \mu \mathrm{g}$ ) of samples and Ascorbic acid (AA) were added to these test tubes and made up to $3 \mathrm{ml}$ with Tris-HCl buffer (16mM; pH 8.0).Ascorbic Acid (AA) was used as reference standard for comparison.Phenazine methosulphate solution was added $(40 \mu \mathrm{M} ; 1 \mathrm{ml})$ to each test tubeThe reaction mixture was incubated for $5 \mathrm{~min}$ at RT. A control without the test compound was maintained.The absorbance of the samples was measured at $560 \mathrm{~nm}$. [Gulcin , et al., 2005). Super oxide radical scavenging activity was calculated using the following formula:

$\%$ SO radical scavenging activity $=\frac{(\text { control OD }- \text { sample OD })}{\text { control OD }} \times 100$.

\section{Estimation of nitric oxide radical Scavenging}

\section{Activity}

Various concentrations $(10 \mu \mathrm{g}, 50 \mu \mathrm{g}$ and $100 \mu \mathrm{g})$ of samples and Butylated hydroxy anisole (BHA) were taken in different test tubes and made up to $3 \mathrm{ml}$ with $0.1 \mathrm{M}$ phosphate buffer ( $\mathrm{pH}$ 7.2).Sodium Nitroprusside $(5 \mathrm{mM})$ prepared in buffered saline (pH7.2) was added $(1 \mathrm{ml})$ to each tube.The reaction mixture was incubated for $30 \mathrm{~min}$ at RT. A control without the test compound, but with an equivalent amount of methanol was maintained.After $30 \mathrm{~min}$, $1.5 \mathrm{ml}$ of above solution was mixed with $1.5 \mathrm{ml}$ of Griess reagent (1\% Sulphanilamide, 2\% phosphoric acid and $0.1 \% \quad \mathrm{~N}-1-$ Naphthylethylenediamine dihydrochloride). The absorbance of the samples was measured at $546 \mathrm{~nm}$. . [Kumar, et al., 2008)] Nitric oxide radical scavenging activity was calculated using the following formula:

$\%$ NO radical scavenging activity $=(\underline{\text { control OD }- \text { sample OD }}) \times 100$. control OD 


\section{RESULTS AND DISCUSSIONS Phytochemical analyses}

The results of the evaluation of phytochemical screening of methanolic extracts of Scleichera oleosa and Scoparia dulcis revealed the presence of carbohydrates, glycosides, polysaccharides, proteins, steroids, alkaloids, triterpenoids, tannins, lipids, oils, and flavanoids . Saponins were found to be present in the methanolic extract of Schleichera oleosa but were absent in both the extracts of Scoparia dulcis. These constituents are responsible for the curative nature of Schelichera oleosa against itching, head ache, malaria, skin diseases etc. which could make the plant useful for treating different ailments and having a potential of providing useful and safe drugs for human use.

Table 1. Proximate Phytochemical composition of Methanolic and aqueous extracts of S.Oleosa and S.dulcis

\begin{tabular}{|l|c|c|c|c|}
\hline & \multicolumn{2}{|c|}{ S. oleosa } & \multicolumn{2}{c|}{ S.dulcis } \\
\hline Phytochemicals & Methanolic & Aqueous & Methanolic & Aqueous \\
\hline Carbohydrates & + & + & + & + \\
\hline Glycosides & + & + & + & + \\
\hline Polysaccharides & + & - & - & - \\
\hline Proteins & + & + & + & + \\
\hline Alkaloids & + & + & + & + \\
\hline Steroids & + & + & + & + \\
\hline Triterpenes & + & - & + & + \\
\hline Flavanoids & + & - & + & + \\
\hline Tannins & + & + & + & + \\
\hline Oipid & + & + & + & + \\
\hline
\end{tabular}

\section{Total phenolic, flavonoid contents and total antioxidant activity}

As reported by Mahakunakorn et al., (2004) these phenolics and flavonoids compounds present in extracts are believed to intercept the free-radical chain of oxidation and donate hydrogen from the phenolic hydroxyl groups, thereby forming stable free radicals, which do not initiate or propagate further oxidation.

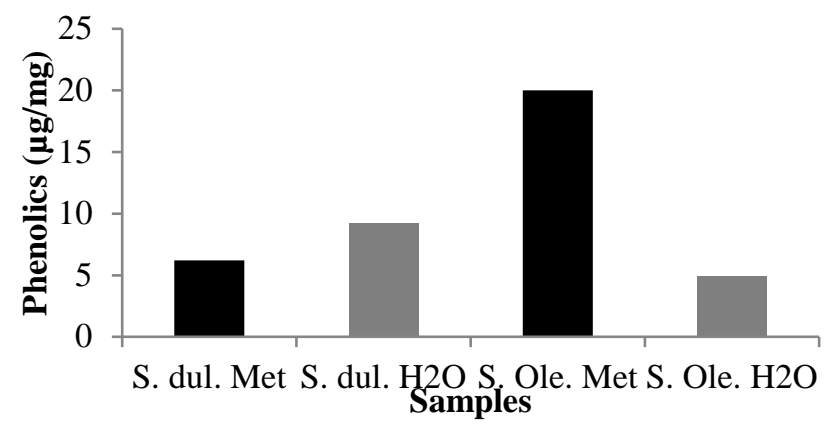

Fig.1. Total phenolics contents of S.oleosa and $S$. dulcis

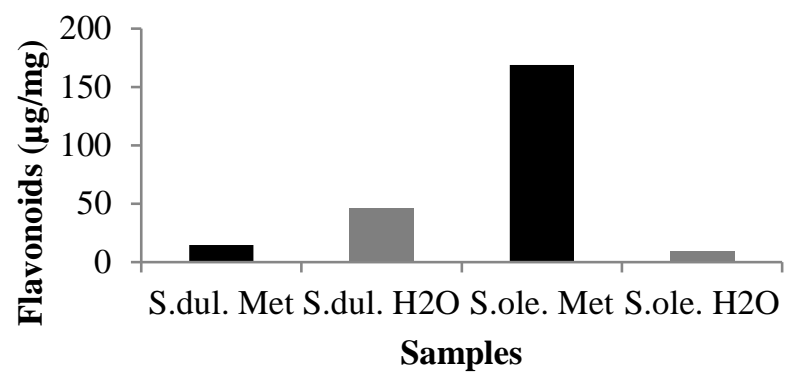

Fig. 2.Flavonoid content of leaf extracts of S.dulcis and S.oleosa

\section{Total antioxidant capacity}

DPPH, hydroxyl, superoxide and nitric oxide radical scavenging activity are the most widely used methods for screening the antioxidant activity of plant extract. The extracts displayed a creditable DPPH scavenging (Fig-4) hydroxyl radical scavenging (Fig-5) superoxide ion scavenging (Fig-6) and nitric oxide scavenging activity (Fig-7) for their respective extract. However, in the entire four tests methanol extract displayed better scavenging activity than aqueous extract for this study. These findings suggest that the plant extracts could have contained phytochemicals that is capable of donating hydrogen to a free radical in order to remove the odd electron which is responsible for the radical's reactivity. 
Table.2.Total anti-oxidant property analysis of leaf extracts of S.dulcis and S.oleosa.

\begin{tabular}{cccccc}
\hline $\begin{array}{c}\text { Concentration } \\
(\boldsymbol{\mu g})\end{array}$ & $\begin{array}{c}\text { S.dul. } \\
\text { Met }\end{array}$ & $\begin{array}{c}\text { S.dul. } \\
\text { H2O }\end{array}$ & $\begin{array}{c}\text { S.ole. } \\
\text { Met }\end{array}$ & $\begin{array}{c}\text { S.ole. } \\
\text { H2O }\end{array}$ & $\begin{array}{c}\text { BH } \\
\text { A }\end{array}$ \\
\hline 10 & 2.9 & 6.05 & 7.8 & 1.85 & 5 \\
50 & 7.4 & 13.1 & 19.35 & 5.15 & 14.5 \\
100 & 12.8 & 19.9 & 25.5 & 7.7 & 28 \\
\hline
\end{tabular}

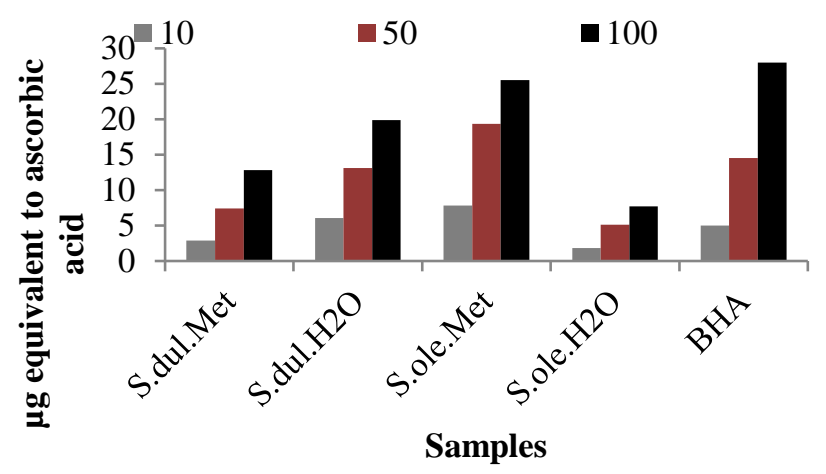

Fig.3. Showing total anti-oxidant property of extracts of S.dulcis and S.oleosa

\section{Free radical scavenging assay}

Interception of free radicals is mainly by radical scavenging, The scavengers include various antioxidants like carotenoids, flavonoids, etc., (Sies, 1996). In the present study, aqueous and methanolic extracts were found to be effective scavengers against DPPH radical. Their activities increased in a concentration dependent manner (Fig. 4). The methanolic extracts showed higher DPPH radical scavenging activity, than aqueous extracts. The $\mathrm{DPPH}$ radical scavenging activity of methanolic extracts of $S$. oleosa was shown to be $54.94 \%$ at $100 \mu \mathrm{g} / \mathrm{ml}$ and of aqueous extract was $5.92 \%$ at 100 $\mu \mathrm{g} / \mathrm{mg}$. For S.dulcis the \% of free radical activity in methanolic extract and aqueous extract in 100 $\mathrm{gg}$ concentration was $2.98 \%$ and $15.53 \%$ respectively.

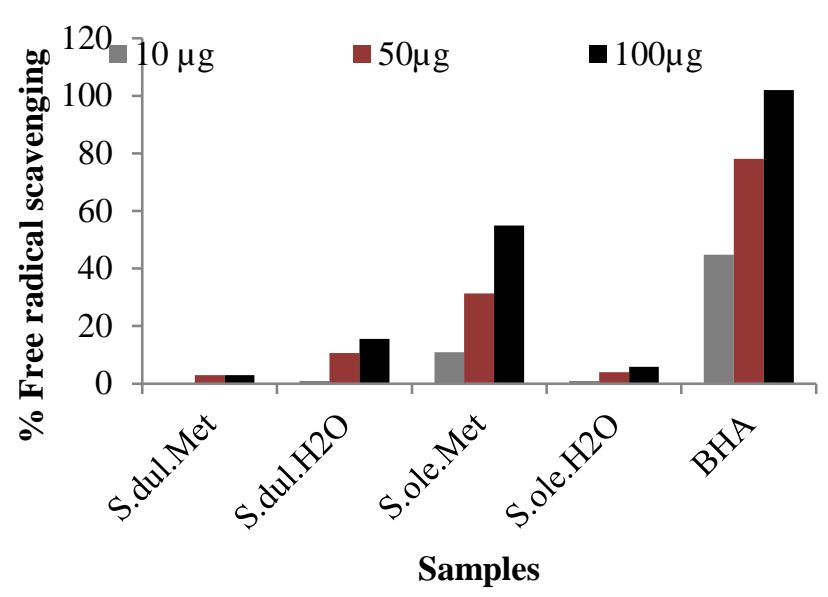

Fig4: Percentage Free radical scavenging activity of S.dulcis and S.oleosa in comparison with BHA.

\section{Hydroxyl radical scavenging activity}

Hydroxyl radicals are the major active oxygen species that cause lipid oxidation and enormous biological damage (Aurand, et al., 1977, Sunil, et al., 2008).The hydroxyl radical scavenging activity of the methanolic and aqueous extracts was studied (Fig. 5). Both extracts exhibited a concentration-dependent scavenging abilities for the hydroxyl radical. Methanolic extract was found to be the more powerful scavenger of the hydroxyl radical, with an inhibition of up to $35.83 \%$ and $17.92 \%$ for S. oleosa and $S$. dulcis respectively at a concentration of $100 \mu \mathrm{g} / \mathrm{ml}$. It is worth mentioning that aqueous extract showed an inhibition of $8.19 \%$ and $11.39 \%$ at a concentration $100 \mu \mathrm{g} / \mathrm{ml}$ for S.oleosa and S. dulcis respectively.

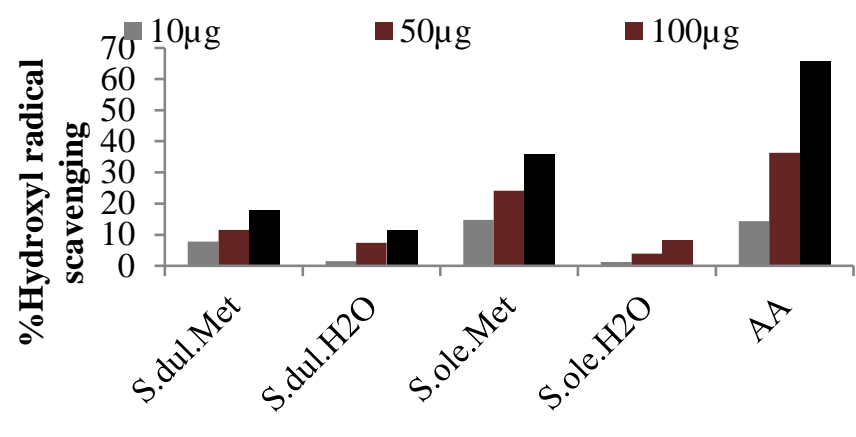

Samples

Fig.5: Percentage hydroxyl radical scavenging activity of S.dulcis and S.oleosa in comparison with Ascorbic acid 


\section{Superoxide anion scavenging activity}

Earlier work on the percentage inhibition of superoxide generation by Citrullus colocynthis at $2500 \mathrm{mg} \mathrm{mL}-1$ concentration was found to be $71.3 \pm$ 3.2\% (p < 0.005), (Sunil et al.,2008).The Superoxide anion scavenging activity of the methanolic and aqueous extracts was explored (Fig. 6). Both extracts exhibited concentration-dependent scavenging abilities for the superoxide anion radical. Methanolic extract was found to be the more powerful scavenger of the superoxide anion radical, with an inhibition of up to $22.58 \%$ at a concentration of $100 \mu \mathrm{g} / \mathrm{ml}$ and aqueous extract showed an inhibition of 3.23 at a concentration $100 \mu \mathrm{g} / \mathrm{ml}$ for S.oleosa and S.dulcis showed only $4.03 \%$ and $3.23 \%$ scavenging of superoxide anion radical at a concentration of $100 \mu \mathrm{g} / \mathrm{ml}$ for methanolic and aqueous extracts respectively

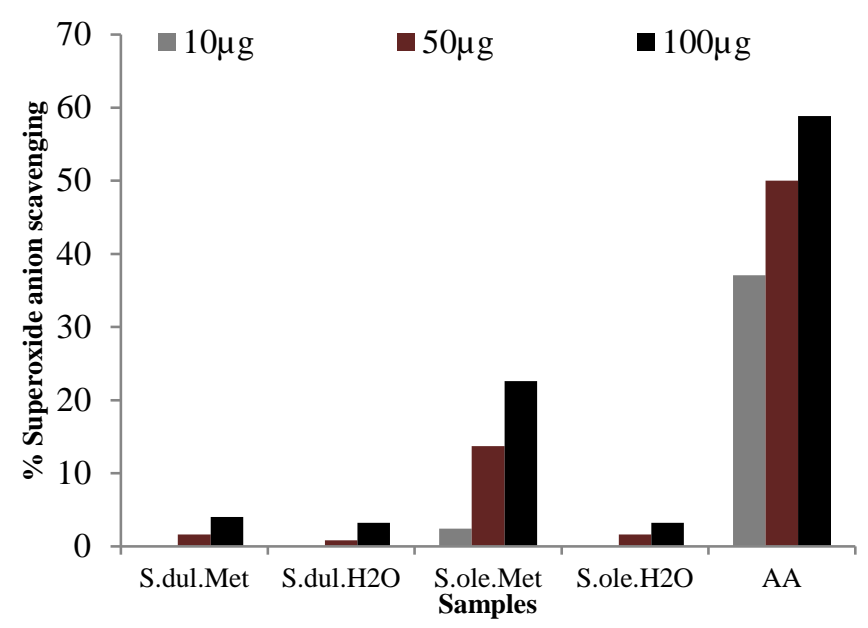

Figure.6. super-oxide anion radical scavenging activity of S.dulcis and S.oleosa

\section{The nitric oxide scavenging activity}

Earlier works have shown nitric oxide scavenging capacity of different plant parts (Wankupar, et al., 2015). Methanolic and aqueous leaf extracts of Schleichera oleosa and Scoparia dulcis exhibited concentration-dependent scavenging abilities for the nitric oxide radical. M.E was found to be the more powerful scavenger of the nitric oxide radical, with an inhibition of up to $33.81 \%$ at a concentration of $100 \mu \mathrm{g} / \mathrm{ml}$ and A.E showed an inhibition of $31.43 \%$ at a concentration $100 \mu \mathrm{g} / \mathrm{ml}$ in case of S.oleosa. Nitric oxide scavenging activity was 5.71\% in M.E of S.dulcis and 5.24\% for A.E.

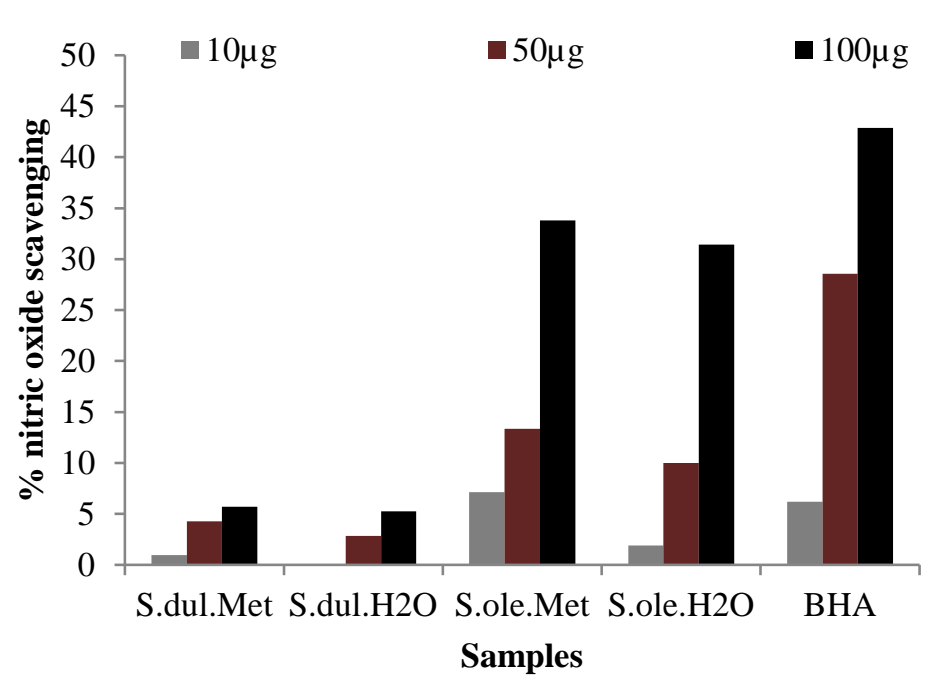

Fig.7.Nitric oxide scavenging assay of leaf extracts of S.dulcis and S.oleosa

\section{Conclusion}

Thus summarizing these results, it is evident that S.oleosa has better anti-oxidising capacity than S.dulcis. It is also evident that methanol extracts of $S$. dulcis and $S$. oleosa proved to have superior antioxidant capacity when compared to aqueous extract in this particular study and this may have resulted due to the greater extraction capacity of methanol when used as solvent. Hence, the possibility of using crude extracts of S.oleosa and S.dulcis as antioxidants would greatly reduce the need to obtain pure compounds via expensive industrial purification techniques. Further in depth study of toxicity and dosage may reveal the efficacy of the plants as alternatives to anti-oxidant therapy. On the basis of above studies, it can be concluded leaf of Schleichera oleosa and Scoparia dulcis contains several beneficial compounds such as flavonoids, phenols and tannins. Our studies presented a positive relationship between the free radical scavenging activity, the effective antioxidant capacity displayed by total phenol, flavonoids and antioxidant content in both methanol and aqueous extract which clearly justifies the therapeutic efficacy of both plant leaf extracts as an alternative to synthetic antioxidant. In conclusion, S.oleosa and S.dulcis might be agents with anti-cancer, liver protective and antinflammatory potentials as they show moderate antioxidant activity and should be further investigated in the future. 


\section{ACKNOWLEDGEMENT}

The authors acknowledge the facilities provided by Department of Zoology, Ranchi University , Ranchi, India for carrying out the work.

\section{Bibliography}

1. Halliwell B, Gutteridge JMC. 2003. Free radicals in biology and medicine. Oxford University Press.

2. Mau JL, Chao GR, Wu KT. 2001. Antioxidant properties of methanolic extracts from several mushrooms. J Agric Food Chem. 49: 5461-5467.

3. Niki E, Shimaski H, Mino M.1994. Antioxidantismfree radical and biological defense Tokyo. Japan: Gakkai Syuppan Center.

4. Sophy Jose and M.P. Sinha. 2016. Phytochemistry and antibacterial efficacy of Schleichera oleosa on some human pathogenic bacteria. J. The Eco Scan Special issue, Vol. IX: 00-00.

5. Yevgenia Shebis, David Iluz, Yael Kinel-Tahan, Zvy Dubinsky and Yaron Yehoshua. 2013. Natural antioxidants: function and sources.Food Nutr Sci, 4: 643-649.

6. Gülçin I, Oktay M, Küfrevioglu ÖI, Aslan A. 2002. Determination of antioxidant activity of lichen Cetraria islandica (L) Ach. J Ethnopharmacol. 79: 325-329

7. Freire SMF, Emim AJS, LAPA AJ, Souccar C, Torres LMB.1993.Analgesic and anti-inflammatory properties of Scoparia dulcis L. extract and glutinol in rodents. Phytother Res,7:408-414.

8. Hayashi T, Kawasaki M, Miwa Y, Taga T, Morita N. Antiviral agents of plant origin. III. Scopadulin, a novel tetracyclic diterpene from Scoparia dulcis $\mathrm{L}$. Chem Pharm Bull,1990; 3: 945-947.

9. Ahsan M, Islam SKN, Gray AI, Stimson WHC. Cytotoxic diterpenes from Scoparia dulcis. J Nat Prod, 2003; 66(7): 958-61.

10. Palanuvej C, Vipunngeun N. Fatty acid constituents of Schleichera oleosa (Lour) Oken seed oil. J Health Res. 2008;22:203-2.

11. Sophy Jose and M.P. Sinha. 2017. Study of Antibacterial Efficacy of Methanolic and Aqueous Leaf Extracts of Scoparia dulcis on Some Human Pathogenic Bacteria. Int.J.Curr.Microbiol.App.Sci. 6(1): 423-432.

12. Manna A, Abalaka ME. Preliminary screening of the various extracts of Physalis angulala (L.) for antimicrobial activies. Spectrum J, 2000 7(2):119-125.

13. Trease, G. E. and Evans, W. C. 2002. Pharmacognosy. 15th Ed. Saunders Publishers, London. p. 42.

14. Sofowora, A. 2008. Screening Plants for Bioactive Agents. In: Medicinal Plants and Traditional Medicinal in Africa. 3rd Ed. Spectrum Books Ltd, Sunshine House, Ibadan, Nigeria. p. 134.

15. Malick, C.P. and Singh, M.B. (1980). In: Plant Enzymology and Histoenzymology. Kalyani Publishers. New Delhi. P 286)
16. Helmja K., Vaher M., Gorbatšova J. and Kaljur and M. (2007). Characterization of bioactive compounds contained in vegetables of the Solanaceae family by capillary electrophoresis. Proc. Estonian Acad. Sci. Chem., 56; (4) 172-186.

17. Prieto P., Pineda M. and Aguilar M. (1999). Spectrophotometric quantitation of antioxidant capacity through the formation of a phosphomolybdenum complex: specific application to the determination of vitamin E1. Analytical Biochemistry. 269: 337-341

18. Kumar S., Kumar D., Manjusha, Saroha K., Singh N. and Vashishta B.(2008): Antioxidant and free radical scavenging potential of Citrullus colocynthis (L.) Schrad. methanolic fruit extract, Acta. Pharm. 58; 215-220.

19. Klein, S. M.; Cohen, G.; Cederbaum, A. I. (1991). Production of formaldehyde during metabolism of dimethyl sulphoxide by hydroxyl radical generating system. Biochemistry, 20, 6006-6012.

20. Gulcin I., Alici H.A. and Cesur M. (2005). Determination of in vitro antioxidant and radical scavenging activities of Propofol. Chem. Pharm. Bull. 53(3); 281-285.

21. P. Mahakunakorn, M. Tohda, Y. Murakami, K. Matsumoto, H. Watanabe, 2004, Antioxidant and free radical scavenging activity of Choto-san and its related constituents, Biol. Pharm. Bull., 27, pp. 38-46.

22. Sies H. (Ed.) Antioxidants in Disease, Mechanisms and Therapy, Academic Press, New York, 1996.

23. L. W. Aurand, N. H. Boonme and G. G. Gidding. Superoxide and singlet oxygen in milk lipid peroxidation, J. Dairy Sci. 60 (1977) 363-369.

24. Sunil Kumar,Dinesh Kumar, Manjusha, Kamal Saroha, Nidhan Singh, Bhoodev Vashishta. Antioxidant and free radical scavenging potential of Citrullus colocynthis (L.) Schrad. methanolic fruit extract. J. Acta Pharm. 58 (2008) 215-220

25. Wankupar Wankhar, Sakthivel Srinivasan, Ravindran Rajan , Sheeladevi Rathinasamy. Evaluating in vitro antioxidant activity and GC-MS analysis of Scoparia dulcis Linn (Scrophulariacae). J. Applied Pharmaceutical Science Vol. 5 (07), pp. 029034, July, 2015 